\title{
PKM BAGI KELOMPOK TANI NANAS DAN KELOMPOK PKK DESA PEMATANG TUJUH KECAMATAN RASAU JAYA KABUPATEN KUBU RAYA KALIMANTAN BARAT
}

\author{
PKM For Groups Farmers of Pineapple and PKK Groups Pematang Tujuh Village Rasau \\ Jaya Sub-district Kubu Raya District West Kalimantan \\ Dedi Herdiansyah ${ }^{1)}$, Ichsan ${ }^{2)}$ \\ ${ }^{1}$ Pengajar Jurusan Administrasi Bisnis, Politeknik Negeri Pontianak \\ ${ }^{2}$ Pengajar Jurusan Teknologi Hasil Perkebunan Politeknik Negeri Pontianak
}

\begin{abstract}
Pematang Tujuh Village is a village in Rasau Jaya I District which has the potential of local plants, namely pineapple. Pineapple in this area has not been processed into various food preparations. The purpose of this activity is to provide skills and knowledge to process pineapple into jam, syrup, jelly candy and dried candies. The method used is two stages, namely by presenting / oral speeches about material and product processing practices. The results obtained are jams, syrups and dried candies preferred by all consumers, while candy jelly is favored by 18 people and is not favored by 2 consumers.
\end{abstract}

Keywords: PKK, pineapple, processed pineapple

\begin{abstract}
ABSTRAK
Desa Pematang Tujuh merupakan desa di Kecamatan Rasau Jaya I yang memiliki potensi tanaman lokal yaitu nanas. Nanas di wilayah ini belum diolah menjadi berbagai olahan pangan. Tujuan kegiatan ini adalah memberikan peningkatan keterampilan dan pengetahuan dalam mengolah nanas menjadi selai, sirup, permen jelly dan manisan kering. Metoda yang digunakan menjadi dua tahapan yaitu dengan cara presentasi/orasi oral terhadap materi dan praktek pengolahan produk. Hasil yang diperoleh adalah selai, sirup dan manisan kering disukai oleh seluru konsumen, sedangkan permen jelly disukai oleh 18 orang dan tidak disenangi oleh 2 orang konsumen.
\end{abstract}

Kata Kunci: PKK, nanas, olahan nanas

\section{PENDAHULUAN}

Rasau Jaya merupakan satu kecamatan yang berada di wilayah kabupaten Kubu Raya Propinsi Kalimantan Barat. Kabupaten Kubu Raya adalah kabupaten baru hasil pemekaran dari Kabupaten Pontianak pada tahun 2007. Mulai tahun 2008 Rasau Jaya ditetapkan sebagai Kawasan Terpadu Mandiri dengan luas kecamatan $111.070 \mathrm{Km}^{2}$. Wilayah ini menaungi enam desa yaitu Desa Pematang Tujuh I, Desa Pematang Tujuh II, desa Pematang TujuhIII, desa Rasau Jaya Umum, desa Pematang Tujuh IV dan desa Bintang
Mas dengan jumlah penduduk sebanyak 23.599 jiwa. Selain tanaman kelapa dan jagung, wilayah ini memiliki tanaman nanas juga menjadi tanaman unggulan dan primadona bagi masyarakat desa pematang Tujuh. Hasil panen tanaman nanas dijual dalam bentuk segar dipasar-pasar sekitar Rasau Jaya (20\%) dan sisanya dijual kekota yaitu pasar Flamboyan dan Pasar Dahlia.

Sasaran Kegiatan pengabdian pada masyarakat (PKM) ini ditujukan pada kelompok PKK dan kelompok tani Desa Pematang Tujuh yang telah memiliki 8 kelompok tani yang berasal dari 6 dusun yaitu dusun Suka Damai,dusun Suka Bakti, 
dusun Rejo Agung, dusun Purwodadi, dusun Kebun Jeruk dan dusun Bina Karya. Pada prinsipnya masing-masing kelompok tani saling bekerjasama dan saling membantu memecahkan masalah yang terjadi berkaitan dengan budidaya tanaman lokal serta penjualan secara tradisonal saja belum ada bahasan dikelompok tersebut terhadap pengembangan pada industri hilir.

Berdasarkan survei yang dilakukan Desa Pematang Tujuh kurang mendapatkan pembimbingan dan pelatihan IPTEK untuk mengolah produk yang lebih variatif dan bernilai ekonomis, sehingga merupakan kegiatan yang sangat positif dalam perbaikan kearah pengembangan (Pujimulyani, 2009).

Mitra merupakan organisasi aktif yang rutin mengadakan pertemuan, sehingga peningkatan pengetahuan dan keterampilan harus terus diberikan untuk memajukan kualitas hidup mitra dari sisi ekonomis terkait bidang hilirisasai produk olahan.Permasalahan mitra pada hakikatnya adalah perolehan informasi, pembimbingan dan arahan mengenai sistem wirausaha sederhana, keterampilan dan keahlian, yang sangat minim, sehingga harus diberikan solusi pemecahan nyata .Penyampaian ilmu secara formal dan informal dengan teoritis dan praktek terhadap seluruh kegiatan kewirausahaan merupakan permasalahan pokok yang akan diselesaikan.

\section{BAHAN DAN METODE}

\section{Bahan}

Bahan utama adalah nanas matang dan nanas mentah yang diperoleh dari kelompok tani setempat sedangkan bahan lainnya dibeli dipasar yang berada di Kota Pontianak. Bahan lain yang dimaksud adalah: gula pasir, gula merah, pewarna makanan, vanili, pandan, garam, agar-agar, maezena, kayu manis, cengkeh, bunga pehkak, cabe besar.

\section{Alat}

Peralatan yang digunakan meliputi: dandang besar, gelas literan, pengemas cup sirup dan selai, kompor gas, mangkuk, parang, pisau, panci, kuali, pengaduk, saringan, timbangan, blender, kuali, sealer, pisau, baskom, oven, talenan, cup, oven pengering, nyiruk, serbet, tisu, celemek, paltsik PP,PE, baskom, sutil, bak besar, ember, sendok.

\section{Metoda pelaksanaan}

Kegiatan pengabdian dilaksankan di aula desa Pematang Tujuh Kecamatan Rasau Jaya Kabupaten Kubu Raya Kalimantan Barat.Peserta yang hadir berjumlah 20 orang.Pelaksanaan kegiatan ini dibagi menjadi dua tahapan yaitu dengan cara presentasi/orasi oral terhadap seluruh materi. Presentasi berisi penjelasan tentang seluruh tahapan proses pengolahan produk yang akan dilatihkan serta mengenai efisiensi penggunaan bahan baku dalam berproduksi. Presentasi dilanjutkan dengan praktek agar mitra memahami hal yang dimaksudkan.Mitra yang hadir dibagi menjadi 4 kelompok kecil dengan pengerjaan masing-masing produk yang berbeda, dengan harapan dapat lebih detail dalam penguasaan materi olah yang dilatihkan.

\section{Aspek Proses Produksi Olahan}

\section{Pengolahan selai}

Buah nanas matang yang sudah dikupas kemudian dibersihkan dari kulitnya kemudian dipotong menjadi beberapa bagian dan dicuci hingga bersih, diblender untuk menambah tekstur buah nanas menjadi sangat halus. Siapkan wajan untuk memasak bubur buah nanas, ditambahkan gula pasir putih, perasan air jeruk lemon dan juga serbuk kayu manis jika diinginkan, diaduk hingga tercampur semua, tunggu kurang lebih 30 menit. Bila sudah mengental aduk secara cepat, hentikan pemanasan jika konsistensi selai telah diperoleh (Fachruddin, 2008) 


\section{Pengolahan sirup}

Nanas yang telah dikupas kemudian dihaluskan dengan blender bersama 1 liter air hingga benar-benar halus (10 menit) dan disaring untuk memisahkan ampasnya. Setelah disaring ditambahkan gula pasir halus untuk selanjutnya dimasak hingga mendidih sambil diaduk terus. Setelah dingin disaring kembali untuk menghilangkan sisa serat yang tertinggal, kemas dalam botol plastic dan simpan dalam lemari pendingin.

\section{Pengolahan permen jelly}

Buah nanas yang digunakan untuk pembuatan jelly dipilih nanas yang masak optimal dan tidak luka atau busuk. Nanas yang sehat dan masak optimal dikupas kulitnya dan dihilangkan matanya sampai bersih.Nanas kupasan kemudian dicuci dengan air hingga bersih. Nanas yang sudah bersih dihancurkan sampai bentuk bubur.Bubur nanas dimasak sampai mendidih kemudian ditambah gula pasir sebanyak $50 \%$ sampai larut.Bubur nanas masak disaring dengan menggunakan kainair hasil saringan dimasak dan ditambah pektin. Pektin yang digunakan sebanyak 1 gram/100gr. Pemasakan diteruskan sampai kental sambil diaduk dan dicetakn (Margono, 2000).

\section{Pengolahan manisan kering}

Buah nanas yang telah bersih dari kulit dan kotoran lainnya dipotong sesuai selera.Rendam dalam larutan garam selama 30 menit, cuci dan tiriskan, selanjutnya rendam kedalam air kapur selama 1 jam, cuci dengan air bersih dan tiriskan. Pada bagian lain siapkan larutan gula dan masak hingga mengental selanjutnya masukan potongan empulur nanas yang telah bersih, masak hingga larutan gula mongering, angkat dan jemur dibawah sinar matahri selama 3 hari sampai gula muncul pada bagian permukaan empulur.

\section{HASIL DAN PEMBAHASAN}

Produk yang dihasilkan berjumlah empat jenis yaitu sirup, selai, permen jelly dan manisan kering. Penilaian konsumen terhadap produk yang dihasilkan ditampilkan pada Tabel 1.

Tabel 1. Penilaian konsumen terhadap produk selai, sirup, permen jelly, manisan

\begin{tabular}{lcc}
\hline \multirow{2}{*}{ Nama Produk } & \multicolumn{2}{c}{ Penilaian Konsumen } \\
\cline { 2 - 3 } & Menerima & $\begin{array}{c}\text { Tidak } \\
\text { Menerima }\end{array}$ \\
\hline Selai & 20 & 0 \\
Sirup & 20 & 0 \\
Permen jelly & 15 & 5 \\
Manisan & 20 & 0 \\
kering & & \\
\hline
\end{tabular}

\section{Selai}

Berdasar penilaian pada Tabel 1 terhadap produk selai, maka selai disukai oleh seluruh peserta pelatihan. Penilaian ini dimungkinkan karena selai yang dihasilkan memiliki rasa asli bahan alami yang digunakan, daya oles yang baik yaitu tidak tertinggal di sendok pengoles, tidak mengalami sineresis yaitu keluarnya air dari selai dan memiliki tampilan trasnparan. Pada pembuatannya tidak ditambahkan bahan pengawet, pewarna dan pengental. Menurut Estiasih dan Ahmadi (2009) karagenan mempunyai sifat sebagai pengental. Umumnya konsumen memberikan komentar bahwa selai dalam pelatihan ini tidak keras seperti yang biasanya mereka hasilkan sehingga tidak hanya dapat digunakan untuk dioles keroti tapi juga dapat dibuat menjadi isian cookies nastar.

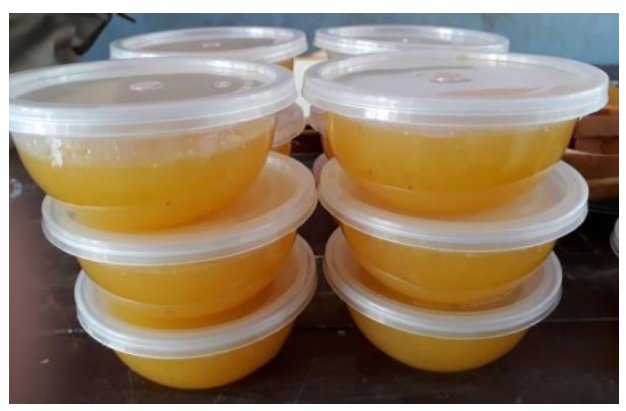

Gambar 1. Selai nanas 


\section{Sirup nanas}

Tampilan sirup yang dihasilkan memiliki warna kuning keemasan, jernih transparan dan rasa asam manis. Warna kuning keemasan berasal dari nanas masak yang digunakan dan tidak digunakan pewarna sintetik, sedangkan rasa asam manis disebabkan oleh kandungan gula dan asam yang terkadung pada bahan baku. Gabungan antara asam dan manis menimbulkan sensasi rasa segar dan melegakan tenggorokan, sehingga seluruh peserta yang memberikan penilaian sangat menyukai produk yang dihasilkan.

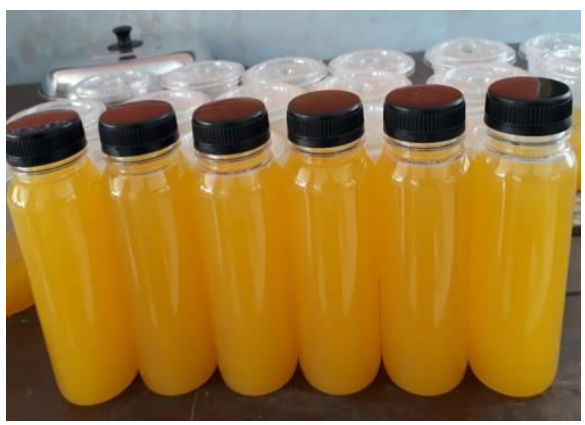

Gambar 2. Sirup nanas

\section{Permen jelly}

Sensasi kenyal yang ditargetkan pada hasil olahan permen jelly sangatlah baik, hal ini dibuktikan dengan tekstur yang dihasilkan lentur, warna yang menarik dan tidak mengalami sineresis. Kesukaan konsumen terhadap permen jelly karena rasa yang ditimbulkan sangat baik.

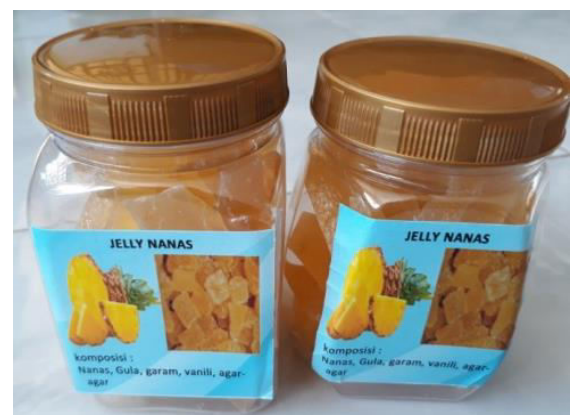

Gambar 3. Permen jelly

\section{Manisan kering}

Manisan kering empulur yang dihasilkan memiliki tampilan yang menarik yaitu timbulnya gula pada bagian permukaan manisan. Rasa yang dihasilkan juga sama yaitu manis dan asam. Kesukaan konsumen utamanya disebabkan karena bahan baku yang digunakan adalah bagian empulurnya. Pengetahuan konsumen selama ini empulur tidak dapat digunakan, namun dalam kegiatan ini dapat diolah menjadi manisan kering.

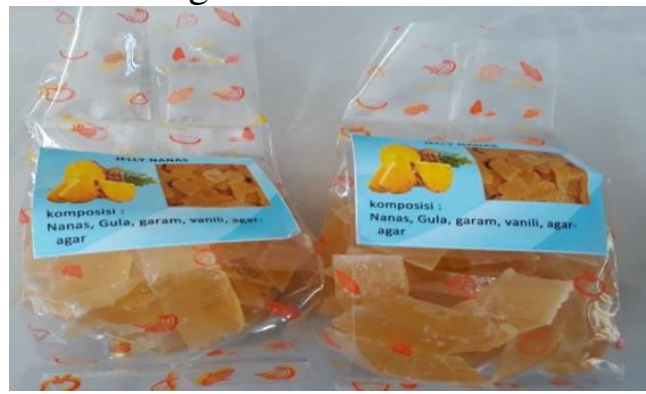

Gambar 4. Manisan kering

\section{KESIMPULAN}

1. Mitra memperoleh peningkatan pengetahuan dan keterampilan dalam pengolahan produk berbahan baku nanas.

2. Produk yang disukai konsumen seutuhnya adalah selai, sirup dan manisan kering.

\section{UCAPAN TERIMA KASIH}

Tim pengabdian masyarakat mengucapkan terimaksih kepada penyandang dana yaitu KEMENRISTEKDIKTI yang telah membiayai seluruh kegiatan pengabdian masyarakat tahun anggaran 2018 dan kepada warga desa Pematang Tujuh atas terselenggaranya kegiatan ini dengan baik dan lancar.

\section{DAFTAR PUSTAKA}

Estiasih, T. \& Ahmadi, K. (2009). Teknologi pengolahan pangan. PT Bumi Aksara.Jakarta.

Fachruddin, L. (2008). Membuat aneka selai. Kanisius. Yogyakarta.

Margono,T. (2000). Selai dan jeli. PT Grasindo. Jakarta.

Pujimulyani, D. (2009). Teknologi pengolahan sayur-sayuran \& buahbuahan. Graha Ilmu. Yogyakarta. 